\title{
Küçük ve Orta Büyüklükteki İşletmelerde Muhasebe Bilgi Sistemleri: Sistematik Bir Literatür İncelemesi ve İçerik Analizi*
}

\author{
Accounting Information Systems in Small And Medium Sized \\ Enterprises: A Systematic Literature Review and Content Analysis
}

\author{
Sanan Jumshudlu' ${ }^{1}$, Nergis Nalan Yakar $^{2}$ (D) \\ ${ }^{1}$ Yüksek Lisans Öğrencisi, İstanbul Üniversitesi, Sosyal Bilimler Enstitüsü, İşletme Anabilim Dalı, İstanbul , Türkiye \\ ${ }^{2}$ Doç. Dr., İstanbul Üniversitesi İşletme Fakültesi, Muhasebe Anabilim Dal, İstanbul, Türkiye \\ ORCID: S.J. 0000-0002-7379-2964; N.N.Y. 0000-0002-6019-5298
}

\section{öz}

Günümüzde teknolojinin hızla gelişmesi ile küreselleşen ekonomide bilgi en büyük güç haline gelmiştir. İşletmeler bilginin önemini anlamış ve rekabet üstünlüğü sağlamak için yatırımlarını bu doğrultuda şekillendirmişlerdir. Bilginin işletme için anlamlı olması ve etkin kullanılabilmesi için bilginin işlenmesi gerekmektedir ki, burada bilgi sistemleri devreye girmektedir. Bu çalışmada, işletmelerin başarısı için hayati önem taşıyan muhasebe bilgi sistemi ve ülkeler için hem ekonomik hem de sosyal açıdan büyük önem taşıyan Kü̧̈ük ve Orta Büyüklükteki İşletmeler (KOBI’ler) ile ilgili teorik bilgiler verildikten sonra KOBİ’lerde muhasebe bilgi sistemleri hakkında yapılmış akademik çalışmalar içerik analizi ile incelenmiş ve sonuçlar ve öneriler ortaya konmuştur. Bu çalışma kapsamında incelenen makaleler (43 çalışma), ilgili çalışmaların son yıllarda arttı̆̆ını ve genellikle anket çalışması yapıldığını göstermektedir.

Anahtar kelimeler: Bilgi, muhasebe bilgi sistemi, küçük ve orta büyüklükteki işletmeler (kobi'ler), sistematik literatür incelemesi, içerik analizi

\section{ABSTRACT}

Nowadays, with the rapid development of technology, information has become the biggest power in the globalizing economy. Businesses have understood the importance of knowledge and shaped their investments in this direction to provide a competitive advantage. For the information to be meaningful and effective, it is necessary to process the information in which information systems are involved. In this study, after giving theoretical information about accounting information systems which are vital for business success, and Small and Medium Sized Enterprises (SMEs), which are economically and socially important for every country, content analysis has been conducted in the academic papers about accounting information systems in SMEs, and results and recommendations were presented. Papers (43 articles) show that the number of related studies have increased in recent years and usually a questionnaire method was applied.

Keywords: Information, accounting information system, small and medium sized enterprises (smes), systematic literature review, content analysis

*Bu çalışma, "Muhasebe Bilgi Sistemleri: Küçük ve Orta Büyüklükteki İşletmeler Üzerine Bir Araştırma” başıklı yüksek lisans tezinden üretilmiştir.

Başvuru/Submitted: 16.01.2020 Kabul/Accepted: 29.01.2020

Sorumlu yazar/Corresponding author: Sanan Jumshudlu / senan.406@gmail.com

Atıf/Citation: Jumshudlu, S. \& Yakar, N.N. (2020). Küçük ve orta büyüklükteki işletmelerde muhasebe bilgi sistemleri: Sistematik bir literatür incelemesi ve içerik analizi. Muhasebe Enstitüsü Dergisi - Journal of Accounting Institute, 62, 37-50.

https://doi.org/doi.org/10.26650/MED.2020675800 


\section{Giriş}

Günümüzde küreselleşme ile birlikte ekonomik açıdan bakıldığında ülkeler arasındaki sınırlar kalkmış, ticaret serbestleşmiş ve dolayısıyla işletmeler rekabet ortamı ile baş etmek durumunda kalmıştır. İşletmelerin bu koşullarda varlığını sürdürebilmek ve rakiplerinden öne çıkabilmek için kendilerini sürekli geliştirmeleri ve değişimlere ayak uydurmaları gerekmektedir.

Rekabet üstünlüğü sağlamak için en önemli unsurun bilgi olduğunu ifade edebiliriz. Bilginin elde edilmesi ve etkin kullanımı için ise bilgi sistemlerine ihtiyaç duyulmaktadır. Hayatımızın her parçasında yer edinen teknolojinin bu hızlı gelişimi bilgi sistemlerinin de gelişim yolunu açmış ve ona duyulan talebi arttırmıştır. İşletmelerin farklı alanlarında yer alan ve birbirileriyle karşılıklı bağları bulunan yönetim bilgi sistemlerinin işletme performansını önemli ölçüde etkilediği görülmektedir. Yönetim bilgi sistemleri içinde en eski ve en önemli yeri muhasebe bilgi sistemi oluşturmaktadır.

Küçük ve Orta Büyüklükteki İşletmelerin (KOBİ) ülkenin sosyo-ekonomik gelişimi için büyük öneme sahip olduğu dünya genelinde anlaşılmış ve ekonomi içindeki rolü artmıştır. Ayrıca esnek yapısı sayesinde değişen şartlara daha kolay uyum sağlayan KOBI'ler konjonktürel dalgalanmalardan ve ekonomik krizlerden büyük şirketlere oranla çok daha az etkilenmektedir. Bu da zor dönemlerde ülke ekonomisinin toparlanmasında önemli bir etken olmaktadır. Bu yüzdendir ki, KOBI'lerin sorunlarının belirlenmesi ve çözüm yollarının bulunması için ülke yönetimleri çeşitli yöntemlerle destek olmaktadır. Dünya ekonomisinde işletmelerin yüzde doksan beşini oluşturması göz önüne alındığında KOBİ’lerin önemi daha iyi anlaşılmaktadır.

Bu çalışmada, öncelikle bilgi, sistem ve bilgi sistemi kavramları tanımlanmış, yönetim bilgi sistemlerinden muhasebe bilgi sistemi ve diğer işletme fonksiyonları ile ilişkisi açıklanmış, daha sonra KOBİlerin işletme fonksiyonları açısından karşılaştıkları sorunlar üzerinde durulmuştur. Son olarak araştırma kapsamında KOBİ'lerde muhasebe bilgi sistemleri üzerine yazılmış Türkçe makaleler içerik analizi ile incelenerek sonuçları aktarılmış ve önerilerde bulunulmuştur.

\section{Bilgi, Sistem ve Bilgi Sistemi}

Bilgi Türk Dil Kurumu sözlük anlamına göre "Öğrenme, araştırma veya gözlem yolu ile elde edilen gerçek, malumat, vukuf; insan aklının erebileceği olgu, gerçek ve ilkelerin bütünü, bili, malumat” demektir. Bilgi her zaman insanların hayatlarında büyük öneme sahip olmuştur ve zaman ilerledikçe önemi daha da artmıştır. Geçmişte hem bireyler hem de şirketler için maddi varlıklara sahip olmak çok daha önemliyken, günümüzde bilgi daha önemli bir varlığa dönüşmektedir.

Bilgi karar almada stratejik bir öneme sahiptir. Günümüz rekabetçi ortamında kaliteli bilgi işletmenin başarılı olması için büyük avantaj sağlamaktadır. Kaliteli ve yeterli bilgiyle işletme stratejisi arasında gerekli bağ kurmak işletmenin performansını arttırır ve rekabet üstünlüğü sağlar. Dolayısıyla işletmenin amaçlarına ulaşabilmesi için etkin kararlar alması, bu kararların etkinliğini yükseltmek için ise kaliteli bilgiyi doğru yerde, doğru şekilde ve doğru zamanda karar vericilere ulaştırması gerekir (İpçioğlu ve Erdoğan, 2005,s. 90).

Veri, bilgi, öğrenilmiş bilgi ve bilgelik kavramları birbirileriyle ilişkili kavramlardırlar. Bu kavramlar uygulamada birbirinin yerine kullanılmakta ve aynı anlama geldikleri düşünülmekte olmasına rağmen aslında birbirinden farklı kavramlardır. Bu sebepten bilgi kavramını daha iyi açıklayabilmek için ilişkili olduğu veri, öğrenilmiş bilgi ve bilgelik kavramlarının anlamlarının ve aralarındaki ilişkinin bilinmesi gerekmektedir.

- Veri: Veriler, olaylarla ilgili ham gerçeklerdir. Sadece var olur ve varlığının ötesinde kendi içinde bir önemi yoktur. Kullanılabilir olmasından veya olmamasından bağımsız olarak herhangi bir biçimde olabilir (Bellinger, Castro ve Mills 2004).

- Bilgi: Bilgi, karar ve/veya eylem için uygun anlam, ima veya girdi içeren bir mesajdır. Bilgi hem güncel (iletişim) hem de geçmiş (işlenmiş veri) kaynaklardan gelir. Temel olarak bilginin amacı karar vermede ve/veya problemleri çözmede veya bir fırsatı gerçekleştirmede yardımcı olmaktır (Liew, 2013, s. 49-62). 
- Öğrenilmiş bilgi: Öğrenilmiş bilgi, verilerden elde edilen bilgiler üzerine kurulur. Öğrenilmiş bilgi, karar vermeye yardımcı olmak için kullanılabilecek uzman görüşü, beceri ve tecrübe eklenmiş veri ve bilgilerin değerli bir varlıkla sonuçlanacak birleşimidir (Baškarada ve Koronios, 2013, s. 7).

- Bilgelik: Bilgelik, kavramları bir alandan yeni durumlara veya problemlere nasıl uygulayacağınızı anlamanızı sağlayan birikimli bir öğrenilmiş bilgidir. Vizyon öngörüleri ve ufkun ötesini görebilme yeteneği ile en üst düzey soyutlamadır. Herhangi bir durumda eleştirel veya pratik olarak hareket etme yeteneğidir. Bireyin inanç sistemi ile ilgili etik kararlara dayanır (Baškarada ve Koronios, 2013, s. 7).

Şekil 1'deki piramitte bilgeliği, öğrenilmiş bilgiyi, bilgiyi ve veriyi içeren hiyerarşiyi görmekteyiz. Bunların her biri altındaki kategorileri de içermektedir. Bu kavramlardan veri "kim? ne zaman? nerede?" sorularına, bilgi "ne?" sorusuna, öğrenilmiş bilgi “nasıl?” sorusuna, bilgelik ise "neden?” sorusuna cevap vermektedir. Ortalama insan aklı yaklaşı yüzde kırk veri, yüzde otuz bilgi, yüzde yirmi öğrenilmiş bilgi, yüzde on anlayış ve neredeyse sıfır bilgelikten oluşmaktadır (Ackoff, 1989, s. 3-9).

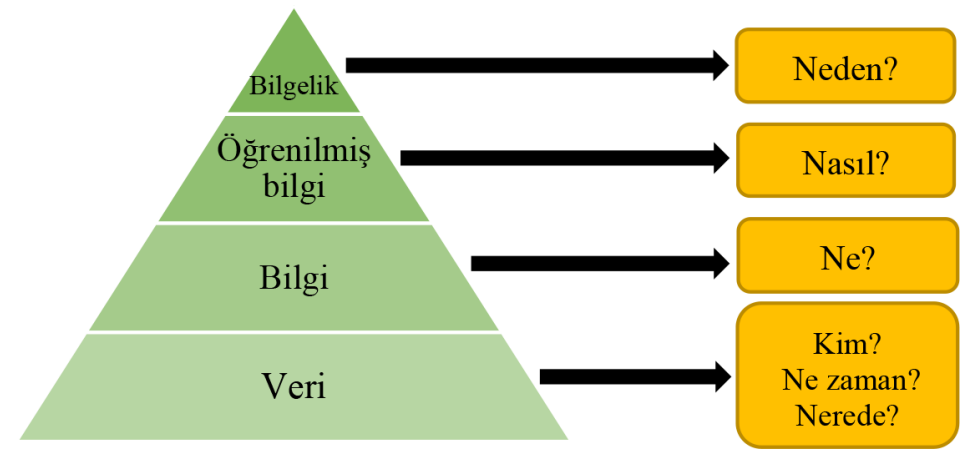

Şekil 1. Veri, Bilgi, Öğrenilmiş Bilgi ve Bilgelik Hiyerarşisi

Kaynak: Yucong Duan, Lixy Shao, Gongzhu Hu, Zhangbing Zhou, Quan Zou, Zhaoxin Lin, "Specifying Architecture of Knowledge Graph with Data Graph, Information Graph, Knowledge Graph and Wisdom Graph", 2017 IEEE 15th International Conference on Software Engineering Research, Management and Applications (SERA), 2017, s. 331.

Sistem, basit olarak birbirleriyle ilişkili ya da etkileşimli elemanların birleştirilmiş bir bütün oluşturmak için bir araya gelerek toplanmasıdır. Başka bir ifadeyle, sistem işletmenin çeşitli kesimlerini birbirleriyle ve işletmeyle karşllıklı ilişkiler içinde ve ana örgütün birer parçası niteliğinde gören yönetim-işletme felsefesinin bir uygulamasıdır. (Peker, 1988, s. 3).

Şekil 2'de, veri işleme döngüsü görülmektedir. Sisteme giren veri sistemde işlenerek depolanır ve bilgi olarak sistemden çıar.

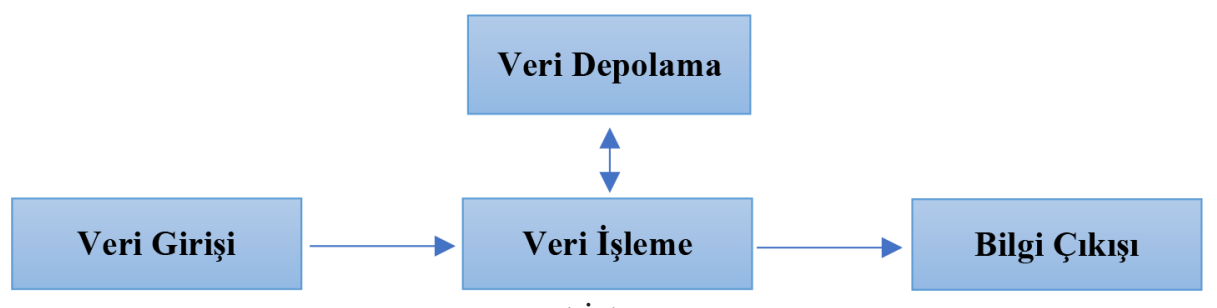

Şekil 2. Veri İşleme Döngüsü

Kaynak: Marshall B. Romney, Paul John Steinbart, Accounting Information Systems, 13. bsk., Harlow, Pearson Education Limited, 2015, s. 26.

Bilgi sistemleri, işletmelerin amaçlarını, operasyonlarını, ürünlerini, servislerini ya da organizasyonların çevresel bağlantılarını değiştirerek rakiplerinin karşısında üstünlük kazanmalarına yardım ederek rekabet avantajı sağlarlar. Bilgi sistemleri veri kaynaklarını girdi olarak alıp belli bir dönüşüm sürecinden geçirerek çıktı olarak bilgi ürünlerini ortaya çıkaran sistemlerdir. 
İşletmelerde bilgi sistemleri; operasyonel bilgi sistemleri, yönetim bilgi sistemleri ve kurum destek sistemlerinden oluşmak üzere üç grupta toplanmaktadır (Ülgen ve Mirze, 2004, s. 356):

- Operasyonel bilgi sistemleri: Kontrol sistemleri, kayıt sistemleri ve ofis otomasyon sistemlerinden oluşan operasyonel bilgi sisteminin amacı işletmenin günlük işlemleri ile ilgili veri kaydı ve paylaşımı olmaktadır.

- Yönetim bilgi sistemleri: Özellikle yönetim kademelerinin işletme ile ilgili alacakları kararlarda, bilgisayar ortamından bilgi sağlayan sistemdir. Karar destek sistemleri ve üst yönetim bilgi sistemleri yönetim bilgi sistemlerine örnek olarak gösterilebilir.

- Kurum destek sistemleri: Diğer iki sistemin dışında kalan destek sistemleri bu grupta toplanmaktadır. Uzman sistemler ve kaynak planlama sistemleri bu gruba örnek olarak gösterilebilir.

Yönetim bilgi sistemlerinden biri olan muhasebe bilgi sistemi, yöneticilerin karar alma süreçlerini etkileyen en önemli sistemlerden biridir.

\section{Muhasebe Bilgi Sistemi ve Diğer İşletme Fonksiyonları ile İlişsisi}

İşletmelerde bilgi sisteminin esas görevi, yönetimin her kademesine ihtiyaç duyulan bilgileri zamanında ulaştırmaktır. Yöneticilerin yönetim kararlarında kullanacakları bilgiler yönetim bilgi sistemleri tarafından karşılanmaktadır. Muhasebe bilgi sistemi de bu yönetim bilgi sistemlerinden en eskisi ve en önemlisidir. Hatta bilgi sisteminin ilk kullanımının muhasebeyle yönetim arasındaki iliş̧kiden kaynaklandığı iddia edilmektedir (Yazıcı, 2010, s. 203-204).

Muhasebe bilgi sistemi, genel veya finansal muhasebe, maliyet muhasebesi ve yönetim muhasebesi gibi geleneksel muhasebe sistemlerini de içeren geniş bir kavramdır. Muhasebe bilgi sistemi, "işletme faaliyetlerini planlamak, kontrol etmek ve yönetmek amacıyla bilgi kullanıcılarının gereksinim duydukları bilgileri sağlamak için verileri ve mali nitelikli işlemleri süreçleyen ve onlara sunan bir bilgi sistemi” olarak tanımlanabilir. Muhasebe bilgi sistemi günümüze kadar en iyi şekilde geliştirilen ve uygulanan bilgi sistemidir (Şahin, 2007, s. 33-34).

Muhasebe bilgi sisteminden elde edilecek finansal bilgilerin faydalı olması için sahip olması gereken niteliksel özellikler Finansal Raporlamaya İlişkin Kavramsal Çerçeve'de temel niteliksel özellikler (ihtiyaca uygunluk, önemlilik, gerçeğe uygun sunum) ve destekleyici niteliksel özellikler (karşılaştırılabilirlik, doğrulanabilirlik, zamanında sunum, anlaşılabilirlik) olarak belirtilmiştir (Kamu Gözetimi Kurumu, 2018, s. 33-34).

Muhasebe bilgi sistemi, işletme fonksiyonlardan aldığg verileri işleyerek bilgiye dönüştüren ve bu bilgileri yine işletme fonksiyonlarına ileten bir işletme fonksiyonudur. Muhasebe bilgi sistemi ile diğer yönetim bilgi sistemleri arasındaki ilişkilerin gösterildiği Şekil 3 'te, diğer yönetim bilgi sistemlerinden elde edilen verilerin muhasebe bilgi sisteminde girdi veya çıktı olarak kaydedildiği görülmektedir. Buradan işletmedeki bütün finansal olaylarla ilgili verilerin muhasebe bilgi sisteminde toplandığı anlaşılmaktadır (Ertaş, 2016, s. 71).

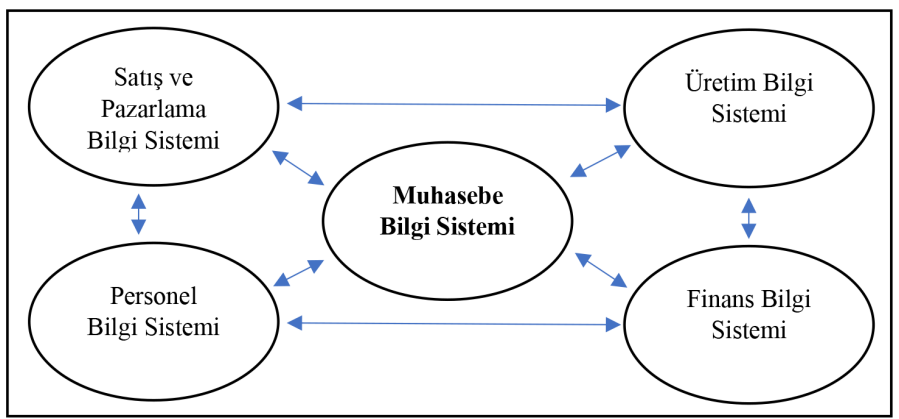

Şekil 3. Muhasebe Bilgi Sistemi ile Diğer Yönetim Bilgi Sistemleri Arasındaki İlişki

Kaynak: Fatih Coşkun Ertaş, Muhasebe Bilgi Sistemi ve Organizasyonu, 4. bsk., Ankara, Seçkin Yayıncılık, 2016, s. 71. 
Muhasebe bilgi sisteminin yöneticilere sunduğu bilgileri üç farklı grupta toplayabiliriz. Bu bilgiler; işlerin nasıl gittiğini gösteren bilgiler, işletmenin sorunlarını gösteren bilgiler ve amaca ulaşmak için gidilebilecek yollardan en etkin yolun hangisi olduğunu anlatan bilgilerden oluşmaktadır. Zaman açısından da muhasebe bilgi sistemi geçmişteki olaylara, devam eden faaliyetlere ve plan ve bütçeler aracıllğıyla gelecekte olması beklenen olaylara veya işletmenin gelecek konumuna ait bilgiler sağlamaktadır (Güney ve Özyiğit, 2015, s. 292-293).

Muhasebe bilgi sistemi, üretim fonksiyonu için alt sistemlerinden maliyet muhasebesini kullanmaktadır. Maliyet muhasebesinin yardımıyla üretim yöneticileri, kararları doğrultusunda kontrol edebilecekleri değişken maliyetlere ve kontrollerinin dışında olmasına rağmen kararlarında önemli etkiye sahip sabit maliyetlere ilişkin bilgiler edinebilmektedirler. Her ne kadar kontrol edilemese de sabit maliyetleri önceden belirleyebilmek yeni bir ürünün üretilip üretilmemesinde veya üretim hacminin artırılıp artırılmamasında üretim yöneticisinin kararını belirlemektedir. Sipariş üzerine üretim yapan işletmelerde ürün çeşitliliği arttığı için değişen maliyetler nedeniyle muhasebe bilgi sisteminin önemi artmaktadır. Muhasebe bilgi sistemi her bir müşteri için ayrı bir maliyet hesaplamakta ve doğru fiyatlandırmanın yapılmasına katkı sağlamakta veya ürünün üretilip üretilmemesi konusunda doğru kararı verebilmek için üretim fonksiyonunun karar vericilerine gerekli bilgileri sağlamaktadır (Ekergil, 2016, s.120-143).

Pazarlama yöneticileri için gerekli olan pazarlama planlaması, satış tahmini, satış yönetimi, ürün yönetimi, tutundurma ve reklamla ilgili ve her türlü mal, satış bölgesi ve satıcılara ilişkin, geçmiş, mevcut ve gelecekteki satışlar ile ilgili maliyetler, stoklar, nakit akımları, alacaklar ve borçlar gibi özel bilgilerle rutin faaliyet ve çalışmalara ilişkin bilgiler muhasebe bilgi sistemi tarafından karşılanmaktadır (Ceran ve Bezirci, 2011, s. 112). Dolayısıyla pazarlama fonksiyonunun etkin bir şekilde çalışmasında muhasebe bilgi sisteminin önemli rolü vardır.

İşletmenin başarıya ulaşmasında veya ulaşamamasında en belirleyici unsur insan unsurudur. Çalışanların bilgi ve becerilerinden en verimli şekilde faydalanmak işletmenin performansını artıracaktır. Çalışanların verimliliğini yüksek tutabilmek için öncelikle adil bir ücretlendirme yapılmalıdır. Adil bir ücretlendirme yapabilmek için ise her bir çalışanın performansı ve işletmeye olan katkısı izlenmeli ve değerlendirilmelidir. Bu aşamada ise insan kaynakları departmanında muhasebe bilgi sisteminden edinilen bilgiler kullanılır.

Muhasebe bilgi sistemi işletmelerdeki mali olaylardan elde edilen bilgileri analiz eder, sentezler ve yorumlar. Muhasebe bilgi sisteminin ürettiği bilgiler finansal kararların alınmasında temel oluşturmaktadır. Üretilen bilgileri yorumlayabilmek için işletmelerde finans yöneticileri muhasebe konusunda bilgi sahibi olmalıdır. Dolayısıyla yeterli muhasebe bilgisine sahip olan finans yöneticileri muhasebe bilgi sisteminin ürettiği bilgileri etkin bir şekilde kullanabilecek ve daha tutarlı kararlar alarak işletmenin daha başarılı olmasını sağlayacaklardır (Ali, 2003, s. 21).

\section{Küçük ve Orta Büyüklükteki İşletmelerde Muhasebe Bilgi Sistemleri Üzerine Bir Araștırma}

\subsection{Araştırmanın Amacı}

"Muhasebe Bilgi Sistemleri: Küçük ve Orta Büyüklükteki İşletmeler Üzerine Bir Araştırma" adlı çalışmanın amacı muhasebe bilgi sistemlerinin KOBİ'ler için önemini ortaya koyarak yapılmış akademik çalışmalar kapsamında KOBİ'lerin muhasebe bilgi sistemleri açısından durumunu ortaya koymak ve gelecekte bu konuda yapılacak çalışmalar için önerilerde bulunmaktır. Bu amaçla bu çalışmada, Türkçe literatürde muhasebe bilgi sistemi ile ilgili KOBİ'ler üzerine yapılmış olan akademik çalışmalar tespit edilmiş ve daha sonra bu çalışmalar incelenerek günümüze kadar KOBí'lerde muhasebe bilgi sistemleri ile ilgili literatürde yapılmış araştırmaların kapsamı ve sonuçları ortaya konarak KOBI'’er ve gelecekte bu konuda araştırma yapacaklar için önerilerde bulunulmuştur.

\subsection{Araştırmanın Kapsam ve Kısıtları}

İşletmelerin performansları, kurumsal yönetim yapıları, yöneticilerin alacakları kararlar gibi birçok konu üzerinde etkili olan muhasebe bilgi sistemleri literatürde birçok açıdan incelenmiştir. Bu araştırma kapsamına muhasebe bilgi sistemleri hakkında Türkiye'deki KOBİ'ler üzerine yapılan Türkçe çalışmalar alınmıştır. Araştırmanın ana kütlesini Türkiye'deki 
bilimsel dergilerde bu konuda yazılmış makaleler oluşturmaktadır. Türkiye'deki KOBİ'ler üzerine yazılmış İngilizce literatürdeki makaleler kapsam dışı bırakılmıştır.

\subsection{Araştırmanın Modeli}

Muhasebe bilgi sistemlerinin KOBİ'ler için önemi göz önüne alınarak KOBI'ler üzerinde yapılan araştırmaların sistematik olarak incelendiği ve analiz edildiği bu araştırmada nitel araştırma yaklaşımı benimsenmiştir. Desen olarak en fazla kullanılan nitel araştırma deseni olan fenomenoloji (olgu bilim) çalışması seçilmiştir.

\subsection{Araştırmanın Yöntemi ve Örnekleme Süreci}

Nitel araştırmada gözlem, görüşme ve doküman incelemesi en yaygın kullanılan veri toplama teknikleridir (Glesne, 2015, s. 64). Nitel araştırmada geçerliliği arttırmak için diğer veri toplama tekniklerinin yanı sıra araştırılan olgu ile ilgili yazılı dokümanlar da tek başlarına ya da diğer tekniklere ek olarak araştırılabilir. Birçok doküman çeşidine ek olarak periyodik kaynaklar, dergiler ve kitaplar da bu analize konu olabilir. (Yıldırım ve Şimşek, 2018, s. 189-190)

Gerçekleştirilen doküman analizi kapsamında, Türkiye'de KOBI'lerde muhasebe bilgi sistemleri ile ilgili yapılmış ve akademik dergilerde yayınlanan makalelerin sistematik bir şekilde tarandığı, ayrıntılı olarak analiz edildiği ve daha sonraki çalışmalar için önerilerde bulunulduğu bu araştırmada sistematik literatür incelemesi türlerinden biri olan bütüncül literatür incelemesi (integrative review) uygulanmıştır.

Bütüncül literatür taraması yapılan bu araştırmanın veri toplama aşamasında ilk olarak, "muhasebe bilgi sistemi", "muhasebe bilgi sisteminin" ve "muhasebe bilgi sistemine" anahtar kelimeleri kullanılarak Dergipark web sitesinde çıkan tüm makalelere ulaşılmıştır. TÜBİTAK ULAKBİM çatısı altında, Türkiye'de yayımlanan akademik dergiler için elektronik ortamda barındırma ve editoryal süreç yönetimi hizmeti sunan bu web sitesinde anahtar kelimeler makalelerin başlığında, öz ve anahtar kelimeler kısımlarında taranmakta ve ilgili tüm makaleler listelenmektedir. Muhasebe bilgi sistemleri ile ilgili elde edilen makale listesinde, KOBI’ler ile ilgili olmayanlar kapsam dışı bırakılmış ve net makale listesine ulaşılmışıtır.

İkinci olarak, KOBİ'lerde muhasebe bilgi sistemleri ile ilgili yapılmış ve Dergipark internet sitesinde taranmayan makaleleri kapsam dışında bırakmamak amacıyla, "Google" ve "Google scholar" web sitelerinde "muhasebe bilgi sistemi" ve "KOBİ" anahtar kelimeleri kullanılarak makaleler listelenmiş ve ilk 10 sayfadaki araştırma kapsamına giren makaleler de araştırmaya dahil edilmiştir. Son olarak, bir ve ikinci aşamada elde edilerek incelenen makalelerin atıfta bulunduğu makaleler gözden geçirilmiş ve araştırma kapsamına alınmamış kaynaklar veri setine eklenmiştir. Araştırmanın devamında bütüncül literatür analizi kapsamında, elde edilen kırk üç makale üzerinde bulgular ortaya konarak makaleler içerik analizi ile incelenmiştir.

\subsection{Araştırma Bulguları}

Çalışmanın bu bölümünde muhasebe bilgi sistemlerine ilişkin KOBİ'ler üzerine yapılmış akademik çalışmalar tespit edilerek konu, amaç, hipotez, veri toplama tekniği, veri analiz tekniği, sonuçlar gibi çeşitli açılardan çalışmalar hakkında elde edilen bilgiler sunulmuştur.

Yapılan araştırma sonucunda elde edilen makalelerden KOBİ ve muhasebe bilgi sistemi ile ilgili olmayan makaleler kapsam dışı bırakılarak toplam kırk üç makale araştırma kapsamına alınmıştır.

\section{Makalelerin Konular İtibarıla Analizi}

Literatür incelendiğinde çalışmaların belirli başlıklar altında toplandığı görülmüştür. Bu konu başlıkları, araştırma kapsamında her birinden kaç makale olduğu ve her bir konu ile ilgili makalelere ilişkin yazar ve yıl bilgisi Tablo 1'de yer almaktadir. 


\begin{tabular}{|c|c|c|c|}
\hline Konular & Sayı & Yüzde & Makaleler \\
\hline Yönetsel Kararlar & 16 & $\% 37$ & $\begin{array}{l}\text { Yardımcıoğlu, M. (2006), Köse, Y. (2009), Demir, Y., \& Coşkun, D. (2009), Kalmış, H., \& } \\
\text { Dalgın, B. (2010), Yazıc, N. (2010), Kaygusuzoğlu, M., \& Uluyol, O. (2011), Tekşen, Ö. } \\
\text { \& Kalkan, Y. (2012), Akgün, A. İ., \& KILIÇ, S. (2013), Alagöz, A., Öge, S., \& Koçyiğit, } \\
\text { N. (2013), Öz, Y., \& Yavuz, H. (2015), Bayraktaroğlu, H., Sarış, A., \& Kalkan, A. (2015), } \\
\text { Demir, Ö.\& Gül, M. (2015), Gündoğmuş, E. \& Köroğlu, Ç. (2016), Yürekli, E. (2017), Yıldı, } \\
\text { A.\&Ceran, Y. (2018), Dede, A. (2019) }\end{array}$ \\
\hline $\begin{array}{l}\text { Muhasebe Bilgi } \\
\text { S i st e m i n i n } \\
\text { Etkinliğ i }\end{array}$ & 10 & $\% 23$ & $\begin{array}{l}\text { Türk, D., Aygen, F., \& Yıldız, Ş. (2009), Koşan, L. (2011), Mizrahi, R. (2011), Özkan, A., Koç, } \\
\text { F. Ö., \& Çidem, İ. (2013), Hatunoğlu, Z., Akpınar, Y., \& Çelik, A. (2013), Dalgar, H., Tekşen, } \\
\text { Ö., \& Tugay, O. (2014), Atmaca, M., \& Akar, E. (2016), Esmeray, A., \& Dağl1, Ö. B. (2017), } \\
\text { Demir, Ö., \& Tanyıldızı, İ. (2018), Yılmazer, Ö. \& Erdem, Ö. (2019) }\end{array}$ \\
\hline 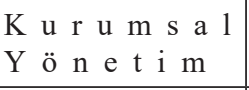 & 5 & $\% 12$ & $\begin{array}{l}\text { Dinç, E., \& Varıcı, İ. (2008), Dinç, E., \& Karakaya, A. (2014), Kaderli, Y., \& Köroğlu, Ç. } \\
\text { (2014), Hacıhasanoğlu, T., \& Erdoğan, A. (2019), Güner, M., \& Kurnaz, E. (2019) }\end{array}$ \\
\hline Performans & 3 & $\% 7$ & $\begin{array}{l}\text { Alagöz, A., Zerenler, M., Yılmaz, B. (2006), Dereköy, F., \& Kalmış, H. (2013), Karahan, A. } \\
\text { (2019) }\end{array}$ \\
\hline Diğer & 9 & $\% 21$ & $\begin{array}{l}\text { Bekçi, I., \& Ömürbek, V. (2007), Yereli, A. N. (2007), Yıldı,, F., \& Eskin, İ. (2012), Aktürk, } \\
\text { A. (2014), Demir, Ö., \& Tanyıldızı, İ. (2017), Alagöz, A., \& Ortakarpuz, M. (2018), Demir, } \\
\text { Ö., Tanyıldızı, İ., \& Bağlığlu, A. (2018), Bulut Deniz M., \& Çukacı Y.C. (2018), Güngörmüş, } \\
\text { A. H. (2019) }\end{array}$ \\
\hline Toplam & 43 & $\% 100$ & \\
\hline
\end{tabular}

\section{Makalelerin Yıllar İtibarıla Analizi}

Araştırma kapsamına giren çalışmalar incelendiğinde muhasebe bilgi sistemleri ile ilgili KOBİler üzerine yapılan çalışmaların 2000'li yılların ortalarında çalışılmaya başlandığı ve sayılarının yıllar içinde genel olarak artma eğiliminde olduğu görülmektedir. (Şekil 4)

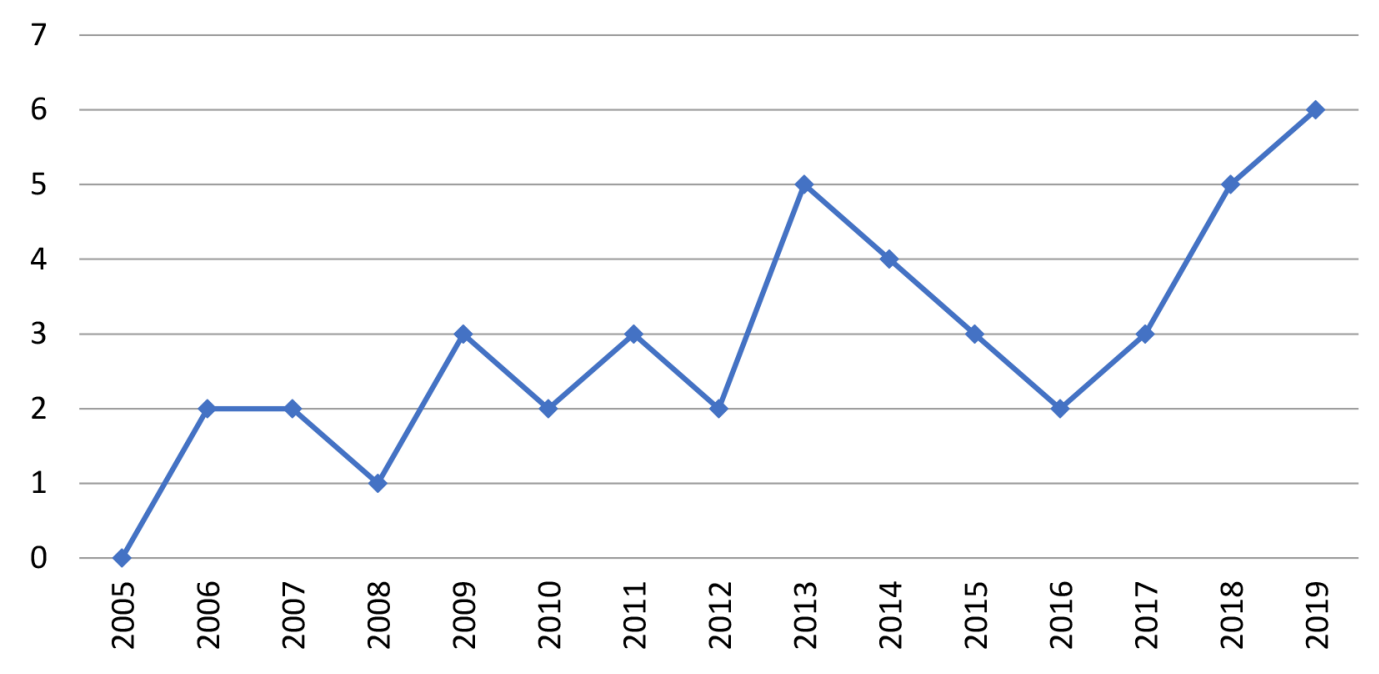

Şekil 4. Yıllar İtibarıyla Makaleler

İlgili oldukları konular dikkate alındığında makalelerin yıllar itibarıyla kümülatif dağılımı Şekil 5'da verilmiştir. Şekilden de görüldüğü gibi işletmelerin yönetsel kararlarıyla muhasebe bilgi sistemleri arasındaki ilişkiyi konu alan çalışmalar diğer konulardaki çalışmalara göre çoğunluktadır. Yönetsel kararlar, muhasebe bilgi sisteminin etkinliği ve diğer konulara ilişkin çalışmalar yıllar içinde düzenli artış göstermiştir. En az ele alınan konu ise muhasebe bilgi sistemleri ile işletme performansı arasındaki ilişkidir. 


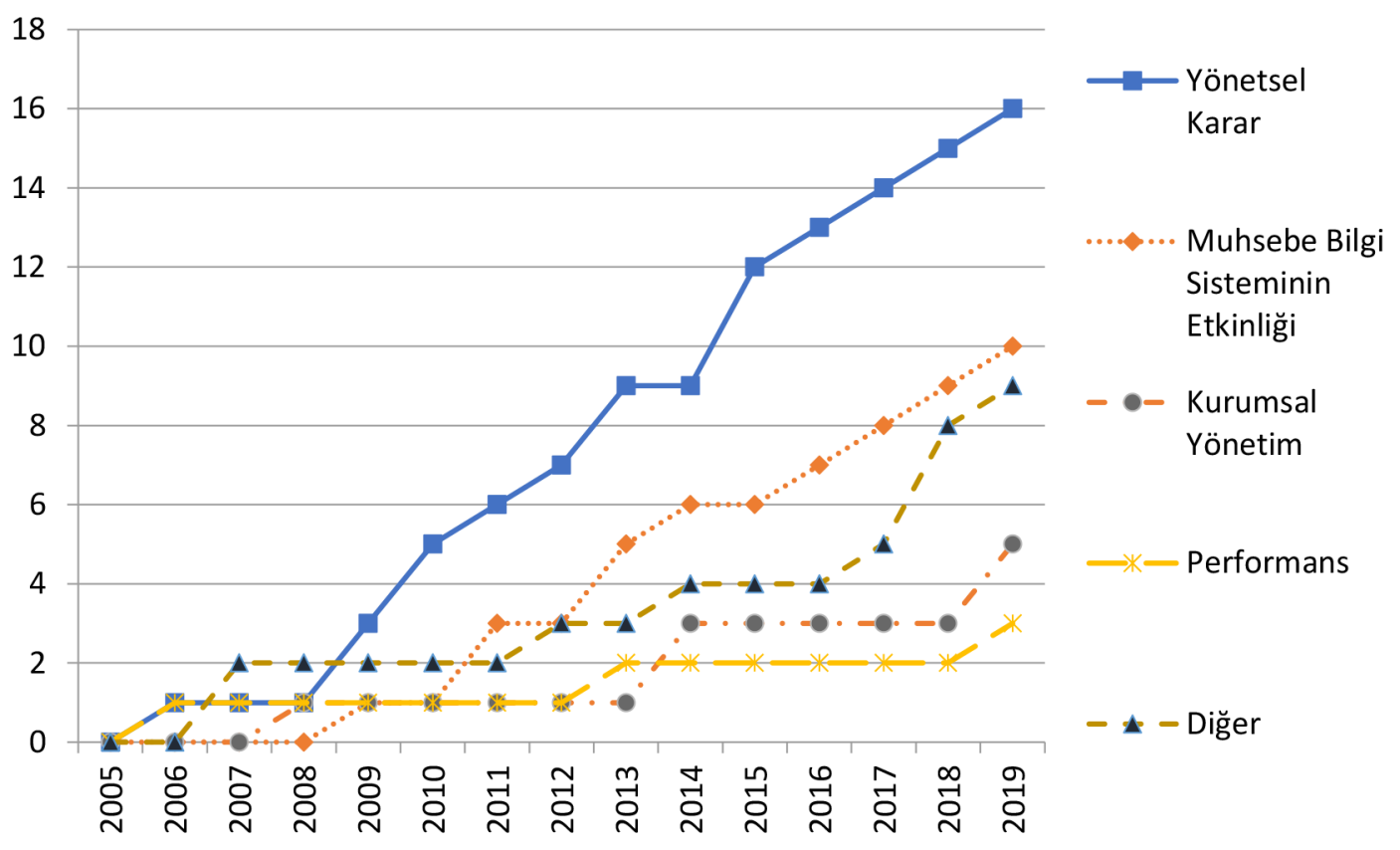

Şekil 5. Yıllar ve Konular İtibarıyla Makaleler (Kümülatif)

\section{Makalelerin Sektörler İtibarıyla Analizi}

Araştırma kapsamındaki çalışmaların hangi sektörlerdeki KOBI’’ler üzerine yapıldı̆̆ı incelendiğinde, çalışmalarda ağırlıklı olarak belirli bir sektör seçilmeden bazı il veya bölgelerdeki tüm KOBI’’lerin ana kütle olarak belirlendiği, Organize Sanayi Bölgelerinde kayıtlı işletmeler üzerinde araştırma yapıldığı tespit edilmiştir. Araştırma kapsamındaki üç makale ele aldıkları konuları teorik olarak açıkladıkları ve belirli bir sektör üzerinde yoğunlaşmadıkları için sektör sınıflandırmasına dahil edilmemişlerdir. Bir makale teorik olmasına rağmen konaklama sektörüne ilişkin bir çalışma içermektedir ve konaklama sektörüne dahil edilmiştir. Araştırma konusunu üretim işletmeleri olarak belirleyen çalışmalarda çeşitli sektörlere ait üretim işletmeleri üzerinde çalışıldığı tespit edilmiştir, ancak özellikle üretim işletmeleri olarak belirlendikleri için sınıflandırmada ayrı olarak gösterilmişlerdir. Bunların dışında konaklama, tekstil ve sağlık başta olmak üzere gıda, çimento, tuz, mermer gibi belirli sektörlerdeki işletmelerin muhasebe bilgi sistemlerine ilişkin çalışmalar yapıldığ 1 saptanmıştır. (Şekil 6)

\begin{tabular}{|l|c|c|}
\hline Tablo 2: Sektörler İtibarılla Makale Sayıları ve Yüzdeleri \\
\hline Sektör & Makale sayısı & Yüzde \\
\hline Çeşitli & 22 & $\% 51$ \\
\hline Üretim & 5 & $\% 12$ \\
\hline Konaklama-Otel & 4 & $\% 10$ \\
\hline Hazır Giyim-Tekstil & 3 & $\% 7$ \\
\hline Sağlik-Hastane & 2 & $\% 5$ \\
\hline Gıda & 1 & $\% 2$ \\
\hline Çimento & 1 & $\% 2$ \\
\hline Tuz & 1 & $\% 2$ \\
\hline Mermer & 1 & $\% 7$ \\
\hline Teorik-Sektör yok & 3 & $\mathbf{\% 1 0 0}$ \\
\hline Toplam & $\mathbf{4 3}$ & \\
\hline
\end{tabular}


Tablo 2'de araştırma kapsamına giren makalelerin yer aldığı sektörlerin adları ve yüzdeleri yer almaktadır. Şekil 6'de ise makalelerin sektörler itibarıyla dağılımı görülmektedir.

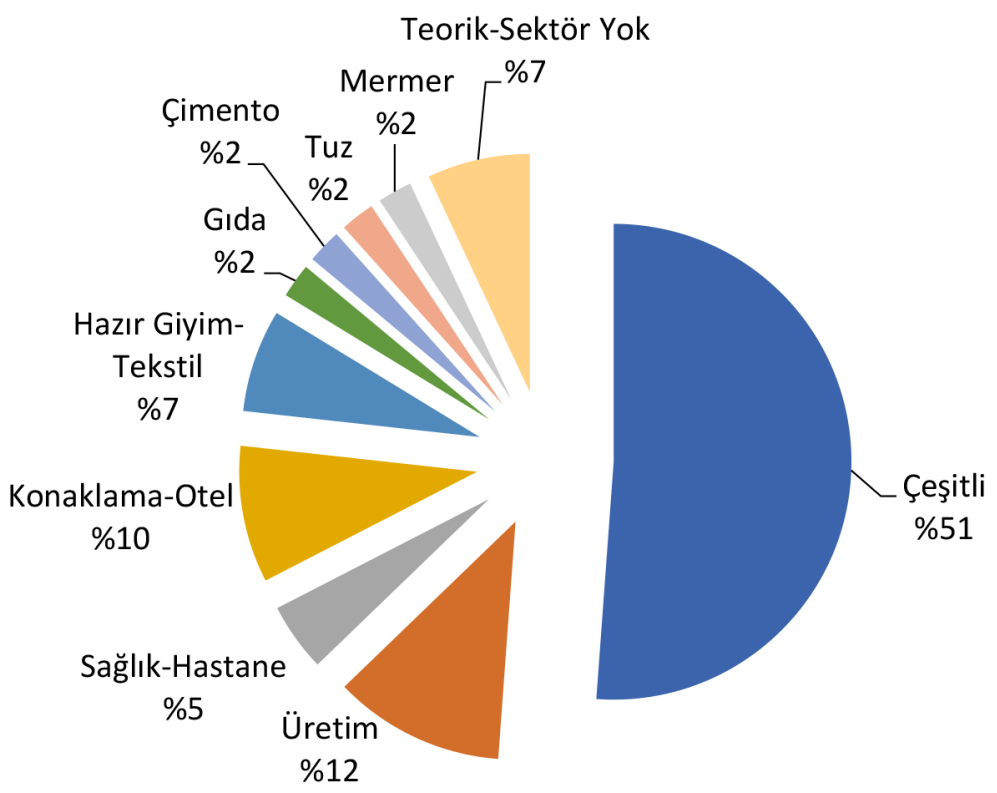

Şekil 6. Sektörler İtibarıyla Makale Sayıları

\section{Makalelerin Veri Toplama Tekniği İtibarıyla Analizi}

Araştırma kapsamındaki çalışmaların büyük çoğunluğunun anket veri toplama tekniğini kullandığ1, 5 çalışmanın ise örnek olay incelemesi deseninde gerçekleştirildikleri tespit edilmiştir. (Şekil 7) Bu 5 çalışmanın ikisi kullandıkları veri toplama tekniği hakkında herhangi bir bilgi vermemiş, diğer üç çalışmada ise derinlemesine görüşme tekniğinin her üçünde, gözlem tekniğinin ise sadece ikisinde kullanıldığı belirlenmiştir. Araştırmalarda deney, odak grup gibi bazı veri toplama tekniklerine ise hiç yer verilmediği saptanmıştır.

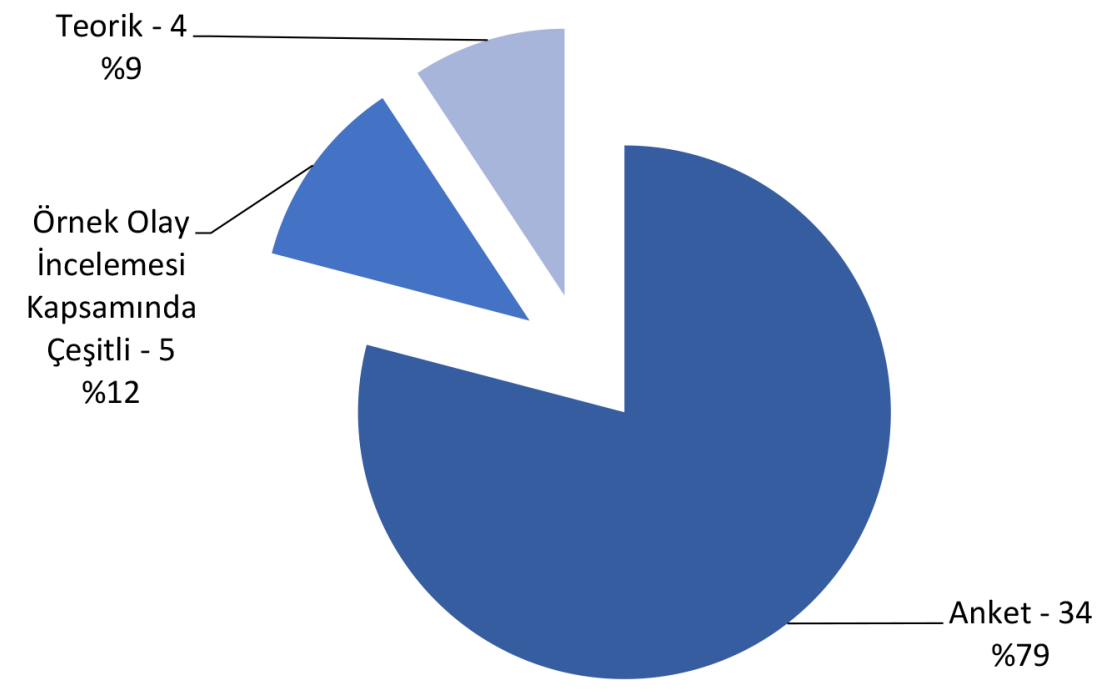

Şekil 7. Veri Toplama Tekniği İtibarıla Makaleler 
Araştırma kapsamındaki makalelerin 2000'li yılların ortalarından başlayarak artma trendi gösterdiği, KOBI'lerde muhasebe bilgi sisteminin işletmelerin yönetim kararları ile ilişkisi ve yönetsel kararlar üzerindeki etkisi ile ilgili araştırmaların daha çok yapıldığı, bu çalışmaları muhasebe bilgi sisteminin etkin kullanımına ilişkin araştırmaların izlediği saptanmıştır. Muhasebe bilgi sistemlerinin KOBI'’lerde iç kontrol, iç denetim, bağımsız denetim süreçleri ile ilişkisine hiç yer verilmediği ve diğer yönetim fonksiyonları ve bilgi sistemleri ile muhasebe bilgi sistemi arasındaki ilişkileri dikkate alan çok az sayıda çalışma olduğu tespit edilmiştir. Makalelerin örneklem seçiminde çoğunlukla belirli bir sektördeki KOBİ’ler yerine belirli bölge veya şehirlerdeki KOBİ'lerin tercih edildiği, veri toplama tekniği olarak ise çoğunlukla anket yönteminin kullanıldığ 1 saptanmıştır. Sektörel bazda muhasebe bilgi sistemi çalışmalarının daha ayrıntılı şekilde yapılarak sektörlere özgü çözüm önerileri getirilmesi ilgili sektörlerdeki KOBI'lerin yararına olacaktır. Ayrıca anket yöntemi yerine nitel araştırma yaklaşımı ile çeşitli desenler seçilerek yarı yapılandırılmış görüşme, gözlem, odak grup gibi veri toplama yöntemleri tercih edilmesi konu hakkında daha ayrıntılı bilgilere ulaşılmasına imkân verecektir.

\section{Sonuç ve Öneriler}

Günümüz işletmelerinde karar alıcıların gereksinim duyduğu doğru, anlamlı ve zamanlı bilgiler ancak başarılı bir muhasebe bilgi sistemi ile elde edilebilir. Küreselleşme ve teknolojik gelişmelerin paralelinde artan rekabet ortamında işletmeler zamanlı doğru kararlar alarak etkin muhasebe bilgi sistemleri ile rekabet avantajı yaratmak zorundadırlar.

Sermaye piyasaları nispeten küçük, gelişmekte olan Türkiye gibi ülkelerde, KOBİ'ler ülke ekonomisi, toplam üretim içindeki payları ve istihdam açısından büyük önem arz etmektedir. KOBİ tanımı birçok kuruluş açısından farklı şekillerde tanımlanmaktadır. Belli bir büyüklükte olan bu tip işletmeler için de rekabeti sürdürebilmek, faaliyetlerine devam edebilmek ve yüksek performans gösterebilmek için işletmelerdeki yönetim bilgi sistemleri ve özellikle de muhasebe bilgi sistemleri önem kazanmaktadır.

$\mathrm{Bu}$ araştırmada, KOBI'lerde muhasebe bilgi sistemlerine ilişkin yazılmış Türkçe makaleler içerik analizi ile incelenmiştir. Çalışmalar kapsamında KOBİ'lerin muhasebe bilgi sistemleri açısından durumu ortaya konarak daha sonraki çalışmalar için önerilerde bulunulmuştur.

Araştırma kapsamına giren makalelerin belli konularda yapıldığı tespit edilmiştir. Bu konular; muhasebe bilgi sisteminin etkinliği, işletmenin kurumsal yönetim yapısı, işletmede alınan yönetsel kararlar, işletmenin performansı ile ilişkileri ve diğer çeşitli konular olarak gruplandırılabilir. KOBI'lerin iç denetim ve iç kontrol, dış denetim faaliyetleri ile muhasebe bilgi sistemi arasındaki ilişki ile ilgili çalışmaya rastlanmamışıı. Ayrıca, işletmelerdeki pazarlama, insan kaynakları, üretim, finans departmanlarının muhasebe bilgi sistemi ile ilişkisini inceleyen çalışmalar kısıtlı sayıdadır.

Araştırma kapsamındaki çalışmaların büyük çoğunluğunun anket veri toplama tekniğini kullandığı tespit edilmiştir. Araştırmalarda deney, gözlem, odak grup gibi çeşitli veri toplama tekniklerinin kullanılmadığ 1 belirlenmiştir. Aynı zamanda sadece 5 çalışma nitel araştırma yaklaşımını benimsemiş ve araştırmalarında örnek olay incelemesi deseni kullanmışlardır.

Araştırma kapsamındaki çalışmalarda ağırlıklı olarak belirli bir sektör seçilmeden bazı il veya bölgelerdeki tüm KOBİ'lerin ana kütle olarak belirlendiği, Organize Sanayi Bölgelerinde kayıtlı işletmeler üzerinde araştırma yapıldığı tespit edilmiştir. Muhasebe bilgi sistemleri ile ilgili KOBİ'ler üzerine yapılan çalışmaların 2000'li yılların ortalarında çalışılmaya başlandığ1 ve y1llar içinde genel olarak artma eğiliminde olduğu görülmüştür.

Araştırma kapsamındaki makaleler incelendiğinde, KOBİ'lerin muhasebe bilgi sisteminin ve bu sistemden elde edilecek bilgilerin öneminin farkında oldukları ancak bu bilgileri yeterli derecede yönetsel kararlarda kullanmadıkları tespit edilmiştir. Araştırmalar etkin muhasebe bilgi sisteminin işletmelerin performansında artı̧̧a neden olacağını ve kurumsallaşmaları yolunda olumlu etkisi olacağını ortaya koymuştur.

$\mathrm{Bu}$ çalışmada gerçekleştirilen nitel araştırmanın devamı olarak KOBI'lerde yarı yapılandırılmış görüşme ve/veya gözlem gibi farklı veri toplama yöntemleri kullanılarak fenomenolojik desendeki nitel araştırmalar yapılabilir. Ayrıca bu çalışma, İngilizce literatür de veri setine dahil edilerek ve Türkçe literatürle karşılaştırması yapılarak daha kapsamlı hale getirilebilir. 
Yapılan bu ve benzeri nitel çalışmalardan hareketle, çeşitli sektörlerdeki KOBİ'ler üzerinde muhasebe bilgi sistemlerinin iç denetim, bağımsız denetim gibi çeşitli alanlarla ilişkileri incelenerek farklı araştırma yöntemleri ile bilimsel çalışmalar yapılabilir. Böylece konu çeşitli açılardan incelenerek ülkemiz ekonomisi için büyük önem taşıan KOBİ’ler için yol gösterici sonuçlara ulaşılmış olacaktır.

Hakem Değerlendirmesi: Dış bağımsız.

Çıkar Çatışması: Yazar çıkar çatışması bildirmemiştir.

Finansal Destek: Yazar bu çalışma için finnansal destek almadığını beyan etmiştir.

Peer-review: Externally peer-reviewed.

Conflict of Interest: The author has no conflict of interest to declare.

Grant Support: The author declared that this study has received no financial support.

\section{Kaynakça}

Ackoff, R. (1989). From data to wisdom. Journal of Applied Systems Analysis, 16, 3-9.

Ali, C. (2003). İşletmelerde finansal yönetim (8. bs.). İstanbul: Ekin Kitabevi.

Baškarada, S., \& Koronios, A. (2013). Data, information, knowledge, wisdom (DIKW): A semiotic theoretical and empirical exploration of the hierarchy and its quality dimension. Australasian Journal of Information Systems, 18(1), 5-24.

Bellinger, G., Castro, D., \& Mills, A. (2004). From data to wisdom. Journal of Applied Systems Analysis, 16(1), 3-9.

Ceran, Y. ve Bezirci, M. (2011). Pazarlama bilgi sistemi - muhasebe bilgi sistemi ilişkisine stratejik bir yaklaşım: Stratejik pazarlama muhasebesi. Selçuk Üniversitesi Sosyal Bilimler Enstitüsü Dergisi, 26, 103-115.

Duan, Y., Shao, L., Hu, G., Zhou, Z., \& Lin, Z. (2017). Specifying architecture of knowledge graph with data graph, information graph, knowledge graph and wisdom graph. 2017 IEEE 15th International Conference on Software Engineering Research, Management and Applications (SERA), 327-332.

Ekergil, V. (2016). İşletme fonksiyonları. Ankara: Anadolu Üniversitesi.

Ertaş, F. C. (2016). Muhasebe bilgi sistemi ve organizasyonu (4. bs.). Ankara: Seçkin Yayıncılık.

Glesne, C. (2015). Nitel araştırmaya giriş (A. Ersoy ve P. Yalçınoğlu, Çev., 5.bs). Ankara: Anı Yayıncılık.

Güney, S. ve Özyiğit, H. (2015). Muhasebedeki verilerin yönetimde kullanılması ve elektronik muhasebe verilerinin yönetim kararlarına rtkisi. Elektronik Sosyal Bilimler Dergisi, 14(53), 279-297.

İpçioğlu, İ. ve Erdoğan, Z. (2005). İşletme stratejisinin belirlenmesinde bilgi yönetimi altyapısının analizi. Sosyal Bilimler Dergisi, 5(2), $89-112$.

Kamu Gözetimi Kurumu. (2018). Finansal Raporlamaya İlişkin Kavramsal Çerçeve. 27 Ekim 2018 tarihli ve 30578 sayıl Resmi Gazete. Erişim adresi: https://www.kgk.gov.tr/DynamicContentDetail/10239/TMS/TFRS-2020-Seti

Liew, A. (2013). Data, information, knowledge, intelligence, wisdom and their interrelationships. Business Management Dynamics, $2(10), 49-62$.

Peker, A. (1988). Modern yönetim muhasebesi. İstanbul: Fatih Yayınevi.

Romney, M. B., \& Steinbart, P. J. (2015). Accounting information systems (13 ${ }^{\text {th }}$ eds.). Harlow: Pearson Education Limited.

Şahin, M. (2007). İşletme bilgi sistemi (5. Bbs.). Eskişehir: Anadolu Üniversitesi.

Ülgen, H. ve Mirze, S. K. (2004). İşletmelerde stratejik yönetim. İstanbul: Literatür Yayınları.

Yazıcı, N. (2010). Bir bilgi sistemi olarak muhasebenin Kobi'lerin yönetim kararlarına etkisi: Erzurum araştırması. Muhasebe ve Finansman Dergisi, 47, 202-212.

Yıldırım, A. ve Şimşek, H. (2018). Sosyal bilimlerde nitel araştırma yöntemleri (11. bs). Ankara: Seçkin Yayıncılık. 


\section{Araştırma Kapsamına Alınan Makaleler}

Akgün, A. İ. ve Kılıç, S. (2013). Muhasebe bilgi sisteminin işletme yönetiminin etkinliği üzerindeki etkisi. Celal Bayar Üniversitesi Íktisadi ve İdari Bilimler Fakültesi Dergisi Yönetim ve Ekonomi,20(2), 21-36.

Aktürk, A. (2014). Otel işletmelerinde muhasebe bilgi sistemini etkileyen güncel gelişmeler (Current events that affect accounting information system in hotels). Muhasebe ve Denetime Bakış Dergisi, 14(43), 107-123.

Alagöz, A. ve Ortakarpuz, M. (2018). Muhasebe bilgi sisteminde kurumsal bilgelik anlayış1. Muhasebe ve Finansman Dergisi, (77), $1-25$.

Alagöz, A., Öge, S. ve Koçyiğit, N. (2013). Muhasebe bilgi sistemi ve karar destek sistemleri ilişkisinin yönetsel karar alma faaliyetlerine etkisi. Selçuk Üniversitesi Sosyal Bilimler Enstitüsü Dergisi, (30), 27-40.

Alagöz, A., Zerenler, M. ve Yılmaz, B. (2006). Konya ilinde faaliyet gösteren küçük ve orta ölçekli işletmelerde muhasebe-finans bilişim sistemleri kullanımının örgütsel verimliliğe etkileri üzerine bir araştırma. Selçuk Üniversitesi İktisadi ve İdari Bilimler Fakültesi Sosyal ve Ekonomik Araştırmalar Dergisi, 6(12), 273-291.

Atmaca, M. ve Akar, E. (2016). İşletmelerde muhasebe bilgi sisteminin etkinliğinin değerlendirilmesi üzerine Çanakkale ilinde bir araştırma. Girişimcilik ve Kalkınma Dergisi, 11(1), 146-164.

Bağlığlu, A., Demir, Ö. ve Tanyıldızı, İ. (2018). Elâzı̆̆ ilindeki KOBİ’lerin maliyet ve yönetim muhasebesi sistemlerinin CHAID analizi ile incelenmesi. Munzur Üniversitesi Sosyal Bilimler Dergisi (MÜSBIDD), 7(13), 77-103.

Bayraktaroğlu, H., Sarıtaş, A. ve Kalkan, A. (2015). KOBİlerde yöneticilerin muhasebe bilgi sistemini kullanım düzeylerinin araştırılması: Burdur ilinde bir uygulama. Finans Politik\& Ekonomik Yorumlar Dergisi, (606), 9-22.

Bekçi, İ. ve Ömürbek, V. (2007). Bilgi teknolojilerinin muhasebe bilgi sistemi uygulamalarına etkisi ve "Konya gıda sektörü üzerine bir araştırma. İstanbul Üniversitesi İktisat Fakültesi Mecmuası, 56(2), 95-120.

Ceran, Y. ve Y1ldız, A. (2018). Otel yönetiminde muhasebe bilgi sistemi ve pazarlama bilgi sisteminden yararlanılarak stratejik pazarlama kararlarının alınması: X otel işletmesinde bir uygulama. Bilge Uluslararası Sosyal Araştırmalar Dergisi, 2(2), 112-129.

Dalğar, H., Tekşen, Ö. ve Tugay, O. (2014). Üretim işletmelerinde muhasebe bilgi sistemi kullanımının incelenmesi: Batı Akdeniz bölgesi araştırması. Muhasebe ve Denetime Bakış Dergisi, 13(41), 49-67.

Dede, A. (2019). Muhasebe bilgi sisteminden elde edilen bilgilerin yorumlanma düzeyi ile yönetim kararlarına etkisi üzerine bir araştırma. Uluslararası Sosyal ve Beşeri Bilimler Araştırma Dergisi, 6(32), 143-154.

Demir, Ö. ve Gül, M. (2015). Üretim yapan KOBI’lerde karar sürecine muhasebe bilgi sisteminin etkileri: TRB1 bölgesinde yapılan bir araştırma. Fırat Üniversitesi Sosyal Bilimler Dergisi, 25(2), 171-192.

Demir, Ö. ve Tanyıldızı, İ. (2018). Üretici KOBİ’lerde muhasebe bilgi sisteminin farkındalığı: Elâzı̆̆ ilinde yapılan bir uygulama. Fırat Üniversitesi Harput Araştırmaları Dergisi, 5(2), 137-162.

Demir, Ö. ve Tanyıldızı, İ. (2017). Muhasebe kültüründe etik değerlerin etkisinin CHAID analizi ile incelenmesi: Elâzığ ilinde yapılan bir araştırma. Fırat Üniversitesi Sosyal Bilimler Dergisi, 27(2), 193-214.

Demir, Y. ve Coşkun, D. (2009). Finansal bilgi sisteminin işletmelerin yönetim fonksiyonu üzerine etkisi: Aydın ili örneği. Uşak Üniversitesi Sosyal Bilimler Dergisi, 2(2), 1-21.

Deniz, M. B. ve Çukacı, Y. C. (2018). Muhasebe bilgi sistemi bağlamında çevre muhasebesinin Türkiye Muhasebe Standartları (TMS) açısından değerlendirilmesi ve bir araştırma. Sosyal Bilimler Dergisi, (27), 70-93.

Dereköy, F. ve Kalmış, H. (2013). Hastanelerde performans ölçümünün muhasebe bilgi sistemiyle ilişkilendirilmesi. Muhasebe ve Finansman Dergisi, (58), 139 - 160.

Dinç, E. ve Karakaya, A. (2014). Muhasebe bilgi sistemi ve kurumsallaşma düzeyi arasındaki ilişki’ye yönelik bir araştırma. Selçuk Üniversitesi İktisadi ve İdari Bilimler Fakültesi Sosyal ve Ekonomik Araştırmalar Dergisi, 14(27), 21-50.

Dinç, E. ve Varıc1, İ. (2008). Muhasebe bilgi sisteminin kurumsallaşma düzeyine etkisi: sanayi işletmeleri üzerine bir araştırma. Afyon Kocatepe Üniversitesi İktisadi ve İdari Bilimler Fakültesi Dergisi, 10(1), 67-85. 
Esmeray, A. ve Dağlı, Ö. B. (2017). Küçük ve orta ölçekli işletmelerde (KOBİ) muhasebe bilgi sistemi: Kayseri'de faaliyet gösteren işletmeler üzerine bir araştırma. İşletme Araştırmaları Dergisi, 9(4), 748-769.

Gündoğmuş, E. ve Köroğlu, Ç. (2016). Pazarlama bilgi sistemi ile muhasebe bilgi sistemi arasındaki ilişskinin stratejik pazarlama muhasebesi açısından incelenmesi: X otel işletmesinde uygulama. Muhasebe ve Denetime Bakış Dergisi, 16(50), 1-20.

Güner, M. ve Kurnaz, E. (2019). Muhasebe bilgi sisteminin kurumsal yönetim uygulamalarına etkisi. Yönetim ve Ekonomi Araştırmalarl Dergisi, 17(1), 297-313.

Güngörmüş, A. H. (2019). Küçük ve orta ölçekli işletmelerin bağımsız denetime yaklaşımlarını etkileyen faktörler: İlgili literatür kapsamında bir derleme çalışması. Muhasebe, Finans ve Denetim Çalışmaları Dergisi, 5(2), 57-72.

Hacıhasanoğlu, T. ve Erdoğan, A. (2019). KOBİlerde kurumsallaşma düzeyinin muhasebe bilgi sistemi üzerine etkisi: İstanbul'da faaliyet yürüten imalatçı KOBİ'ler üzerine bir araştırma. Karadeniz Teknik Üniversitesi Sosyal Bilimler Enstitüsü Sosyal Bilimler Dergisi, 9(17), 79-102.

Hatunoğlu, Z., Akpınar, Y. ve Çelik, A. (2013). KOBİ'lerin yönetiminde muhasebe bilgi sisteminin önemi: Gaziantep ve Kahramanmaraş örneği. Niğde Üniversitesi İktisadi ve İdari Bilimler Fakültesi Dergisi, 6(2), 307-322.

Kaderli, Y. ve Köroğlu, Ç. (2014). İşletmelerde muhasebe bilgi sistemi ile kurumsal yönetim anlayış1 arasındaki ilişki. Muhasebe ve Finansman Dergisi, (63), 21-38.

Kalmış, H. ve Dalgın, B. (2010). Muhasebe bilgilerinin karar almada kullanımının önemi ve Çanakkale'de faaliyet gösteren sanayi işletmelerinde bir uygulama. Muhasebe ve Finansman Dergisi, (46), 112-128.

Karahan, A. (2019). Muhasebe bilgi sistemi kullanımının örgütsel performansa etkisi. Avrasya Sosyal ve Ekonomi Araştırmaları Dergisi (ASEAD), 6(3), 61-80.

Kaygusuzoğlu, M. ve Uluyol, O. (2011). İşletme yöneticilerinin muhasebe bilgilerini kullanım düzeyinin araştırılması. Yönetim Bilimleri Dergisi, 9(2), 297-320.

Koşan, L. (2011). Muhasebe bilgi sisteminin konaklama işletmeleri açısından önemi: Bir olay çalışması. Çağ Üniversitesi Sosyal Bilimler Dergisi, 8(2), 119-133.

Köse, Y. (2009). KOBİ'lerde finansal raporlamanın amaçları ve muhasebe bilgilerinin kullanım düzeyine ilişkin Batı Karadeniz araştırmas1. Muhasebe ve Finansman Dergisi, (41), 114-121.

Mizrahi, R. (2011). KOBİ’lerde muhasebe bilgi sisteminin etkin kullanımı üzerine bir araştırma. Organizasyon ve Yönetim Bilimleri Dergisi,3(2), 307-316.

Öz, Y. ve Yavuz, H. (2015). İşletme yönetiminin aldığı kararlarda muhasebe bilgi sisteminin etkisi ve önemi: Küçük ve orta ölçekli işletmelerde bir araştırma. Cumhuriyet Üniversitesi İktisadi ve İdari Bilimler Dergisi, 16(1), 227--246.

Özkan, A., Koç, F. Ö. ve Çiğdem, İ. (2013). Hastanelerde muhasebe bilgi sistemi etkinliği: İç Anadolu Bölgesinde faaliyet gösteren hastaneler üzerinde bir araştırma. Selçuk Üniversitesi İktisadi ve İdari Bilimler Fakültesi Sosyal Ekonomik Araştırmalar Dergisi, 13(26), $1-22$.

Tekşen, Ö. ve Kalkan, Y. (2012). Yönetim kararlarında muhasebe bilgi sisteminin etkisi: Batı Akdeniz Bölgesi’nde faaliyette bulunan mermer işletmeleri zerine bir araştırma. Muhasebe Bilim Dünyası Dergisi, 14(1), 127-142.

Türk, D., Aygen, F. ve Yıldız, Ş. (2009). Muhasebe departmanında bilgi yönetimi: Sakarya örneği. Muhasebe ve Finansman Dergisi, (44), 236-250.

Yardımcığlu, M. (2006). Muhasebe departmanından elde edilen bilgilerin işlevi ve önemi: Kahramanmaraş tekstil sektöründe bir araştırma. Muhasebe ve Denetime Bakış, 71-108.

Yazıcı, N. (2010). Bir bilgi sistemi olarak muhasebenin kobi’lerin yönetim kararlarına etkisi: Erzurum araştırması. Muhasebe ve Finansman Dergisi, (47), 202-212.

Yereli, A. N. (2007). Muhasebe bilgi sistemlerinin risk yönetimine yönelik bir araştırma. Muhasebe ve Denetime Baklş Dergisi, 7(23), $15-32$. 
Y1ldız, F. ve Eskin, İ. (2012). Yeni Türk Ticaret Kanunu'na Göre KOBİ'lerin muhasebe bilgi sisteminin değerlendirilmesi. Munzur Üniversitesi Sosyal Bilimler Dergisi (MÜSBİD), 4(2), 61-69.

Yılmazer, Ö. ve Erdem, Ö. (2019). Küçük ve orta ölçekli işletmelerin (KOBİlerin) yönetiminde muhasebe bilgi sisteminin yeri ve önemi: Ankara tekstil işletmeleri örneği. Uluslararası Sağlık Yönetimi ve Stratejileri Araştırma Dergisi, 5(2), $184-215$.

Yürekli, E. (2017). KOBİ'lerde Yönetim ve maliyet muhasebesinin stratejik karar alma üzerine etkisi. Muhasebe ve Finansman Dergisi, (73), 137-168 